\section{Eleutherodactylus paulsoni (Hispaniolan Pink-rumped Frog). Conservation.}

Date of observation: 26 July 2010. Location: Haiti: Grand'Anse; 3.8 km N Dame-Marie. Coordinates: 18.57, -74.417. Elevation: $34 \mathrm{~m}$. Voucher: video. This IUCN critically endangered (CR) species has not been seen in about 20 years. It has a wider distribution than most other CR species, being recorded throughout the Tiburon Peninsula of Haiti, but for an unexplained reason it has been rarely encountered in the last three decades. It was found in rotting palm tree vegetation and leaf litter in a forest. Accompanied by Richard Thomas. Thanks to Philippe Bayard and the Audubon Society of Haiti.

S. Blair Hedges, Pennsylvania State University, Department of Biology, 208 Mueller Lab, University Park, Pennsylvania, 16802, USA, sbh1@psu.edu.
Citation: Hedges SB. 2010. Eleutherodactylus paulsoni (Hispaniolan Pink-rumped Frog). Conservation. Caribbean Herpetology 9:1.

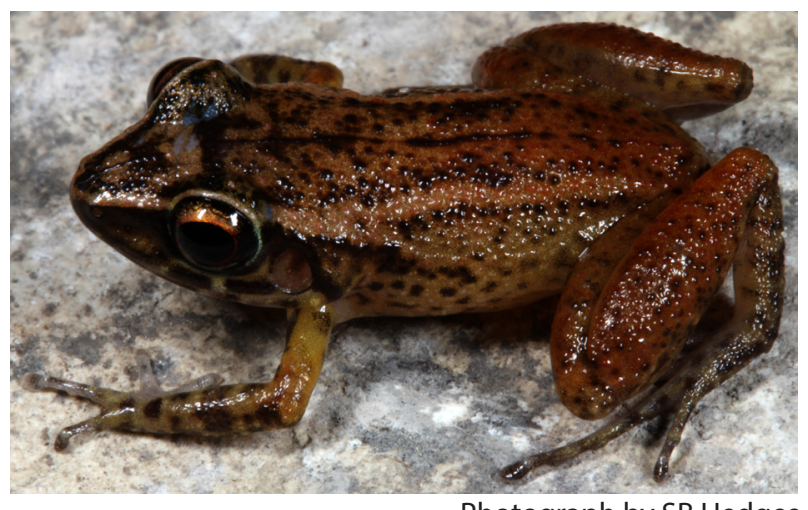

Photograph by SB Hedges

Published online 26 August 2010 